\title{
Chemistry of Energy Conversion and Storage**
}

\section{Dang Sheng Su}

Energy is becoming a big issue in our society fueled by the growing awareness of the finite resources of fossil liquid fuels and the noticeable climate changes resulting from the consumption of fossil fuel. The need to accelerate the introduction of renewable energies in the energy pool has been fostered by the recent oil price crisis and political tension in the Gulf region that created intense social pressure for an accelerated transition from fossil to renewable fuels. At the same time, concerns regarding greenhouse gases have been progressively turned from possibility to reality, and the fraction of world population accessing to a massive use of energy is exponentially increasing. The immense consumptions of energy, either in fossil form or as electricity, in emerging countries such as China and India, have additionally driven the global demand for a sustainable development. The accident of Fukushima, also recalling the past accidents of nuclear power stations, may have re-focused the social, political and scientific interests of future energy scenarios on renewable energies based on solar energy.

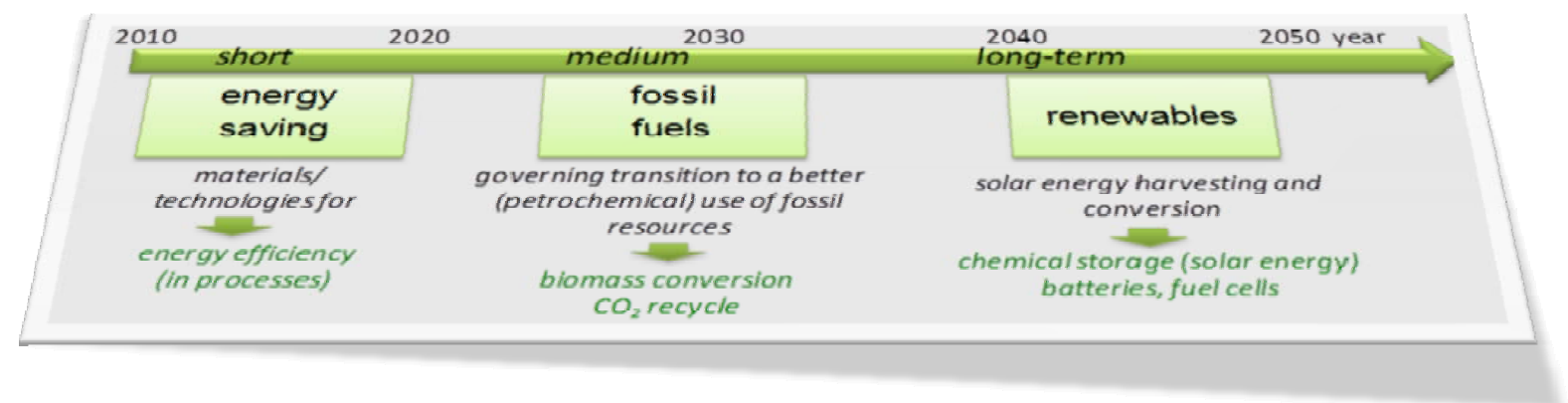

Figure 1 Centi's roadmap of future energy scenario. Reprinted with permission from Ref. 1.

The global primary energy consumption is about $5 \times 10^{14} \mathrm{MJa}^{-1}$ (ref.2). This is a very large number describing the scale of the energy challenge. Until now the major contributions to this large number are still energy based on fossil fuels. No other energy source, neither renewable nor nuclear, could replace fossil fuel energy in short or mid term. This is either due to the un-equivalent development of such technologies (low efficiency, low energy density) or due to the political uncertainty and safety issue (for nuclear energy). It is a general consensus to have a well-considered roadmap of the future energy scenario with the 
final goal to replace fossil energy by renewable energies (Figure 1). Fossil fuel energy remains however for a short term the only energy source world-wide, although the efficiency needs to be increased and the carbon dioxide emission must be drastically decreased. A proper portion of biomass should be integrated in the energy pool, if it does not compete with the food supply, another even more essential issue for mankind. However, looking for alternative and renewable energies could be the only solution for the sustainable development of our society. Therefore, an increasing use of solar energy will become predominant for a longer-term energy scenario, and remains, at least for the current understanding of science, the only solution to the fossil fuel energy under the perspective of sustainability. New concepts, new methods, new materials, new processes and new technologies are required for the new developments ${ }^{3}$ albeit a long way is still to go until we can replace the current energy supply to a certain extend.

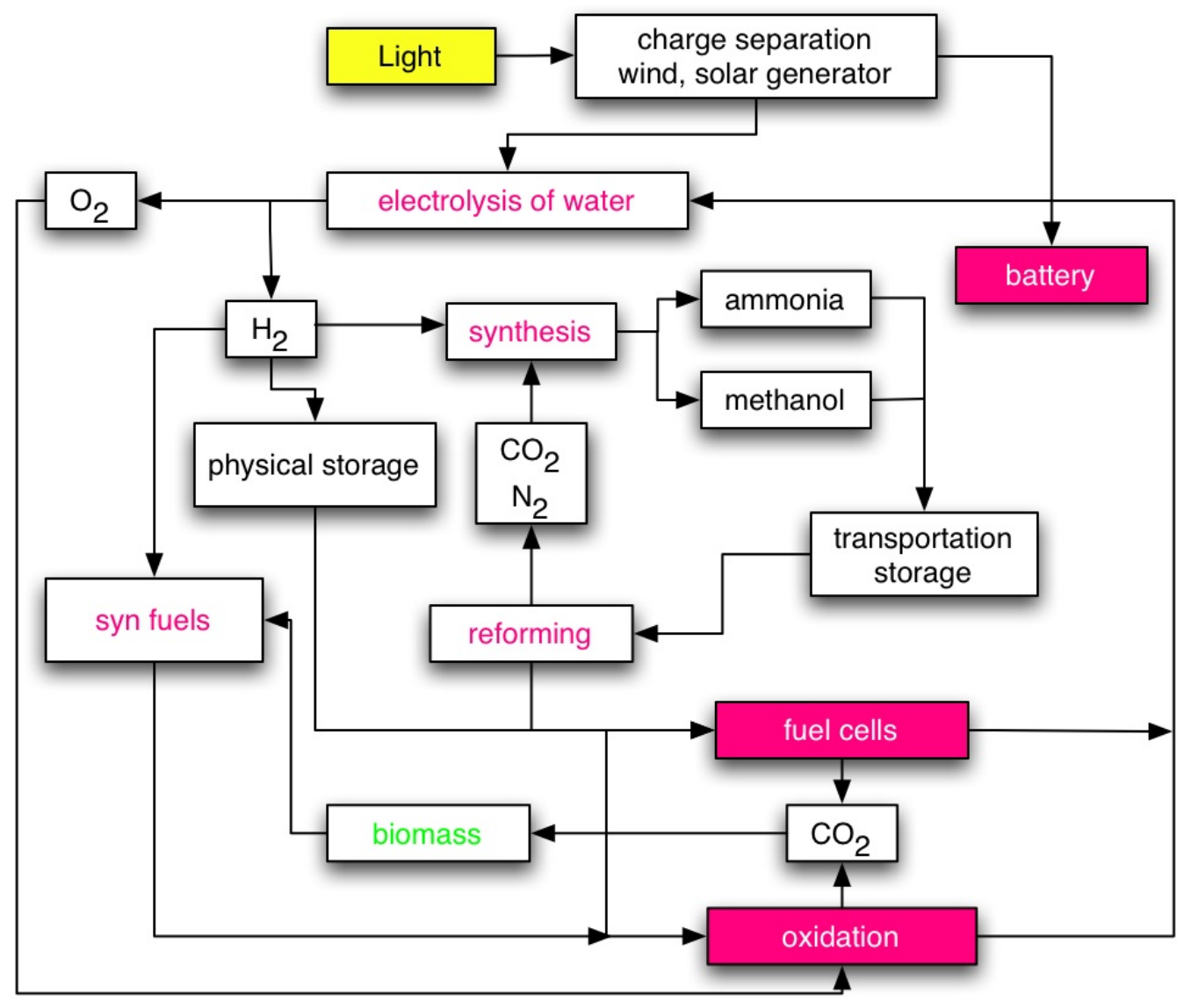

Figure 2 "Energiemix" by Robert Schlögl: an energy scenario for energy storage and conversion based on hydrogens as storage molecules and nitrogen or carbon dioxides as exhaust product. Battery, fuel cell and combustion are the systems with which the primary solar energy will be converted to 
electricity. The German version of this "Energiemix" is published in Die Zukunft der Energie, Editors Peter Gruss and Ferdi Schüth, Verlag C.H. Beck oHG, Munich 2008, pp258.

In a solar energy based renewable energy scenario ${ }^{4}$, primary energy in form of electricity could be produced from solar energy (through photovoltaic), from wind turbine and concentrating solar power (CSP). The strong day-time and seasonal dependence of solar and wind energies requires a storage of the electricity generated. The chemical storage of energy could be the charging of batteries, the production of hydrogen, hydrocarbon, ammonia and other synthesized fuel such as methanol. The chemical storage of energy has a better flexibility and higher energy density (materials for high performance batteries are still under investigation) than, for instance, the mechanical or physical storage of energy. A direct storage of solar energy occurs in nature in biomass, which collects also carbon dioxide. The direct utilization of stored solar energy could be batteries through discharging. The process for indirect utilization of stored solar energy is the fuel cells, and through combustion of synthesized fuels. It should be mentioned here that the electricity covers only one third of our current energy demand. Liquid fuel seems to remain unavoidable for some applications, despite some promising developments achieved for hybrid automobiles.

Both, on the long road to reach the solar energy based energy pool (figure 1, for the short and intermediate term, an essential field is the energy conversion from fossil fuel sources and the storage of the gained energy), and in the solar based "Energiemix" (figure 2), chemistry is indispensable for all efforts to save energy by performing our technical production process with optimized resource utilization, and is the strategic core discipline for all future energy conversion processes that are based on primary solar energy.

- Chemistry can play a relevant role in global primary energy consumption by maximizing the selectivity of molecular transformations and by supporting the minimization of physical loss through adequate material developments.

- Chemistry enables the storage of energy converted by physical process (photovoltaic or wind) in chemical bonds allowing for long term strategic energy reserves and long distance transportation.

- Chemistry can provide solutions for the direct storage of primary electricity from solar and wind source in batteries for operating on mobile applications, and for the chemical storage (redox-flow batteries as one example) buffering on medium and large scales. 
- Chemistry can provide solutions that circumvent the use of precious metal or to minimize their application to the absolutely essential level, a prerequisite for a broad application of fuel cell technologies.

- Chemistry provide, in addition to the improvement of the efficiency of fossil energy and thus the reduction of emission, elegant and safe ways to capture and convert carbon dioxide to fuel, polymers and so on closing the carbon cycle.

- Chemistry energy research enables the identification and verification of ingenious chemical conversion concepts and of materials that create new technologies

How chemistry determines the fate of mankind is reflected by the discovery of the ammonia synthesis and its industrialization, the most important chemical process, called Haber-Boscher process. At the beginning of last century, all civilized nations stand in deadly peril of not having enough to eat. The demanding on food is a demanding of nitrogen fertilizer. It is Fritz Haber who discovered how ammonia, a chemically reactive, highly usable form of nitrogen, could be synthesized by reacting atmospheric dinitrogen with hydrogen in the presence of iron at high pressures and temperatures, and Carl Bosch who subsequently developed it on an industrial scale. The importance of Haber's discovery cannot be overestimated - as a result, millions of people have died in armed conflicts over the past 100 years, but, at the same time, billions of people have been $\mathrm{fed}^{5}$, as it is illustrated in Figure 3. As a secondary contribution to the mankind, the large-scale production of ammonia has facilitated the industrial manufacture of a large number of chemical compounds and many synthetic products ${ }^{6}$. Thus the Haber-Bosch process, with its impacts on agriculture, industry and the course of modern history, has literally changed the world.

The challenge faced to the mankind at the beginning of last century is the shortage of food, but resolved by the Haber-Bosch process. In a highly abstracted description, the $20^{\text {th }}$ century is a century of ammonia. Without ammonia synthesis and thus the production of nitrogen fertilizer, we may not have today's world. This is unfortunately not realized by most people since food supply remains, at least now, not a problem ${ }^{7}$. This century's challenges to the mankind are energy and climate change, both are cross-linked. In a very highly abstracted description, the $21^{\text {th }}$ century is a century of hydrogen and carbon dioxide. Hydrogen may be the core of a solar-energy based energy scenario, and the closing of 
carbon cycle is the only way to maintain our climate. However, we are still at the beginning to revolve the energy and climate challenge of this century.

The challenge of $20^{\text {th }}$ century, i.e., the ammonia synthesis, has produced three related Nobel prizes: Haber in 1918 for for the synthesis of ammonia from its elements, Bosch in 1931 for his contributions to the invention and development of chemical high pressure methods, and Ertl in 2007 for his studies of chemical processes on solid surfaces that disclose the reaction mechanism of ammonia synthesis, a work dated back to 1980 's, 70 years after the Haber's discovery in 1908 . The challenge of $21^{\text {th }}$ century opens promising opportunity for scientists, and the contribution of chemistry is indescribable.

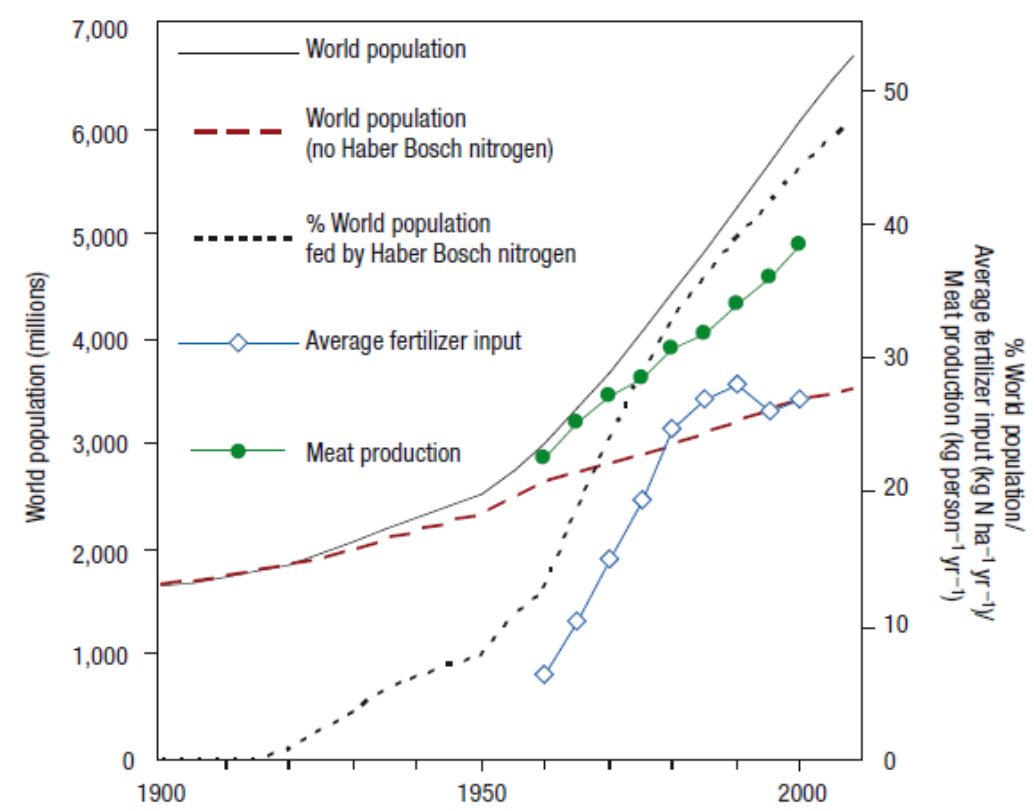

Figure 3 How chemistry changed our life: trends in human population and nitrogen use throughout the twentieth century. Of the total world population (solid line), an estimate is made of the number of people that could be sustained without reactive nitrogen from the Haber-Bosch process (long dashed line), also expressed as a percentage of the global population (short dashed line). The recorded increase in average fertilizer use per hectare of agricultural land (blue symbols) and the increase in per capita meat production (green symbols) is also shown. Reprinted from ref.5.

This "Chemistry of Energy Conversion and Storage" issue contains papers dealing with all the above mentioned aspects. The papers are selected presentations on the 1st International Symposium on Chemistry of Energy Conversion hold from February 27 - March 2, 2011 in Berlin, Germany. This special issue is also the successor issue of "EnerChem" (Energy Chemistry) in ChemSusChem, March 2010, highlighting the most important developments in chemistry of energy conversion and storage of the last two years. 
Acknowledgement: The guest editor expresses his gratitude to the staff of ChemSusChem, and Professor Gabriele Centi, University of Messina, and Professor Changhai Liang, Dalian Universtiy of Technology, for useful discussion.

Reference:

1 G. Centi, S. Perathoner, R. Passalacqua, C. Ampelli, In Carbon-neutral fuels and energy carriers, N.Z. Muradov, T.N. Veziroglu Eds., CRC Press, Boca raton, FL-US, pp. 291.

2 R. Schlögl, ChemSusChem 2010, 3, 209

3 D.S. Su and A. Thomas, ChemSusChem 2010, 3, 120

4 R. Schlögl and F. Schüth, in Die Zukunft der Energie, Herausgeber Peter Gruss und Ferdi Schüth, Verlag C.H. Beck oHG, München 2008, pp246.

5 J. W. Erisman, M. A. Sutton, J. Galloway, Z. Klimont and W. Winiwarter, Nature Geoscience 2008, 1, 636

6 Ammonia is unfortunately used for explosives in weapons, which requires large amounts of reactive nitrogen.

7 Most hungry catastrophes on the earth are man-caused. 